\title{
Legal aspects of telepathology
}

\section{Christian Dierks}

\author{
Dierks \& Bohle, Rechtsanwälte, Institut für \\ Gesundheitssystemfoschung, Kurfürstendamm 57, \\ 10707 Berlin, Germany \\ Tel.: +4930327 78 70; Fax: +4930327 78 777; \\ http://www.dierks-und-bohle.de
}

In some legal surroundings telepathology is considered a breach of registrational barriers. The recommendation of the G 8 states in Europe for required legislation in telemedicine suggests to recognise that the localization of the remote health care professional defines the site not only of licensure but also of liability. This approach must be considered helpful, since it can solve many problems brought about by the doubtful results of private international law and conventions like the European Union (EU) and Lugano Convention. Under today's conditions in private international law it must be considered essential to agree upon a choice of law and stipulate a court of jurisdiction when doing telepathology. However, the opposing aims of insuring the patients claims and avoiding jurisdictions that exceed the local expectations of the medical professional must be reconciled. Data protection and data security are other crucial topics that require attention. Generally speaking, the principles of minimum data exchange, anonymity, pseudonymity and cryptography must be established as a basis for all telepathology procedures. Only when personal data is needed, its use can be legitimated. Written consent of the patient is advised. To guarantee a cross-border security level the regulations of the EU-Data Protection Directive need to be transformed into national law. In practise, cross-border dataflow shall only take place where the security level can be maintained even within the other country. Finally, reimbursement questions must be answered to establish a sound economical basis for telepathology. The spatial distance between the participants may yield the question, whether the service has been rendered to an extent necessary and sufficient for reimbursement. If reimbursement takes place on a cross-border or cross-regional level, severe disturbances of the health systems can occur. Regulation schemes or treaties need therefore to be developed to avoid such disturbances and encompass mutual standards of care as well as methods to balance reimbursement. Keywords: Telepathology, legal aspects, licensing, liability, data protection, data security, reimbursement

\section{Introduction}

Telepathology has undergone a rapid development $[9,12]$. Within the last ten years reports from many countries tell us about the establishment of more and more sophisticated telepathology procedures, e.g., HISTKOM [14], UICC Consultation Centre [16], OLMICOS [14], etc. The distance between the participants in telepathology not only enables a better allocation of pathologist expertise [2,6-12], but also brings about five major legal problems, which are discussed in this contribution [9].

Telepathology, as seen by the lawyer, is characterised by a geographical distance between the tissue or specimen to be evaluated and the pathologist himself $[9,13]$. This gives rise to specific legal issues. Primarily, the distance between the participants may not endanger the quality of the services rendered. Diagnosis according to the state of the art must be ensured. On an international basis the issue of professional medical registration or licensing has to be discussed.

\section{Standard/state of the art}

Under regular, non-telemedicinal circumstances the patient may expect a medical service carried out according to the standard, according to the state of the art. The determination of standards is mainly a medical task, subject to medico-legal control and subject to regional changes and influences. This can bring about the typical cross-border problems of different standards, especially when diagnostics are being performed in a region with a lower medical standard.

One of the key-elements in determining the appropriate standard is the contractual liability of the doctor employed. The patient may rightly expect the standard which prevails at the locus of his main contract partner. A different, potentially lower standard of any other medical person being involved in the background does not have to be accepted, unless this secondary medical person becomes contract partner of the patient himself.

Another problem, widely debated, is brought about by techniques that are based on a non-pathologist's as- 
sistance in preparing the specimen in a situation where a pathologist is not present at the site of the surgery nor in physical contact with the specimen. This procedure also requires measures to be taken, that guarantee the state of the art. If the pathologist may rightly trust on the qualification of the assisting person (e.g., a surgeon) this delegation must be considered irrelevant to the state of the art.

Apart form this a rise in quality may be expected in any scheme involving second opinions. By bringing out his work into the open, encouragement and criticism must be expected which will procure a further development in quality [5].

The G 8 working group on "Recommendations for Legal Action" suggested, that an "International Code of Practise" for telemedicine should be developed to insure adequate quality of telemedicine. Such a code of practise must take into account that telemedicine requires additional and special measures for good quality and standard, such as technical reliability, organisational procurements and documentation [1].

\section{Licensing}

Not only the pathologist's, any doctor's license, enables this medical person to practice medicine. In most countries this right is confined to a certain place. Within the European Community a licensed-doctor may practise anywhere within the member states. There are, however, restrictions possible within his own home-country. E.g., a pathologist licensed to practise in one town within the United Kingdom (UK), may not necessarily do so in another town within the UK, even so he could open his own practice in Germany according to European law. This legal obstacle brings about the question, whether a pathologist may deliver his opinion to a patient located at a place where he himself is not licensed to practise. This scenario seems to be quite a problem for doctors in the United States, who are regularly limited to practise within their state of registration. One of the solutions to this problem, which has also been encompassed in the $\mathrm{G} 8$ resolution, might be to recognise that the locus of the remote healthcare professional assigns the site of licensure and liability. In other words: The pathologist in his very own office may carry out his practice, even via telemedicine, no matter where the patient or the specimen are located. In this scenario the patient would have to be informed about potential drawbacks that can be brought about by applying the medical and legal sur- rounding of the doctor's site to the doctor-patient relationship. In any case, the legal risks for the professional and the patient must be reconciled. It has also been suggested, that bi- or multilateral agreements should assist in overcoming these cross-border problems.

\section{Litigation}

The crucial point for determining litigational aspects in telepathology lies within the differentiation between a first or second opinion diagnosis. The doctor's liability is mainly influenced by his diagnostic statement effect on the further proceedings with the patient. In case that his opinion or diagnosis has a binding effect on the patient's treatment the telepathologist's liability does not differ from any other pathologist's opinion. In case that the telepathologist was merely giving a nonbinding second opinion and if the responsibility for the diagnosis remained in the hands of the first pathologist ("face-to-face" with the specimen) any liability issue will have to be discussed with the latter [15].

Nevertheless, a "shift of control" is possible and will have to be taken into account. Once the telepathologist, who was initially delivering second opinions only, is empowered to be the one in charge for basic diagnostic decisions, liability will focus on him.

As long as the G 8 recommendation is not transformed into any national law (which will presumably take a long period of time) agreements about the control of diagnostic measures, on the choice of law and a stipulation of jurisdiction, preferably in written form, are to be advised.

\section{Data protection}

Data protection and data security are the number one issue in any telemedical application. However, these topics are of no concern, if the data managed is not relating to an identified or identifiable natural person. According to article 2 of the European Committee ECDirective on Data Protection (95/467 EC) and most of the national data protection laws any form of communication with non identifiable data is not subject to the multitude of data protection laws and can therefore easily be carried out. As long as telepathology can be practised with an anonymized or pseudonymized data, most of the problems brought about by data protection and data security will be irrelevant. 
Only in the cases where personal data is required the parties involved are in need to acquire and document the patient's consent. Special attention has to be paid to the requirement, that the patient must be informed about content and extent of the data transferred and the duration of data storage. Last not least, the EC-Directive requires additional consent for any data transfer to a third country without an adequate level of protection (Artt. 25, 26). Even if the EC-Directive has not been transformed into national law within all of the member states, it must be taken into account, that any infringement of this principle may potentially lead to a successful claim against a telepathologist failing to comply.

\section{Reimbursement}

After all the enthusiastic engagement for the development and application of telepathology reimbursement issues become the focus of attention. Whereas most of telemedical services have not yet clearly proven that the additional technical efforts really bring about a substantial reduction of costs, telepathology (and also teleradiology) are an exception: Effectiveness studies have been carried out mainly for these image-oriented subspecialties [4]. Compared to other medical services, where a face-to-face contact is still considered part of the complete service, insurance funds tend to accept telepathology on a larger scale.

Nevertheless, reimbursement for service rendered in another country or within an other health-insurance plan, can yield a severe disturbance of any healthsystem, especially in the EC, where systems are based on a broad variety of regional economical actions. The G 8 working group therefore has recommended the development of bi- and multilateral treaties that supply methods to balance such disturbances by economical means that might even include compensations for cross-border flow of health-insurance funds.

\section{References}

[1] S.V. Buravkov and A.A. Bortnikov, Digital image processing and transmission for teleconsultation in pathology, Telemed (1999), TM 99/024, 200.

[2] V. Della Mea, Internet electronic mail: a tool for low-cost telemedicine (review), J. Telemed Telecare 5 (1999), 84-89.

[3] Einbeck Recommendations, Nr.16, in: Rechtsfragen der Telemedizin, C. Dierks et al., eds, Springer, 2000.

[4] M.J. Field, Telemedicine, a guide to assessing telecommunications, Healthcare (1996), 108.

[5] T. Giesen, Datenschutz bei innerärztlicher Kommunikation: Selbstzweck oder Notwendigkeit?, Aktionsforum Telematik im Gesundheitswesen, Nomos (2000), 61-67.

[6] K. Kayser, M. Drlicek and W. Rahn, Aids of telepathology in intraoperative histomorphological tumor diagnosis and classification, In vivo 7 (1993), 379-382.

[7] K. Kayser and C. Kayser, Telepathology - aspects of social influence and quality control, Elec. J. Pathol. Histol. 3(3) (1996), No. 963-04.

[8] K. Kayser, G. Kayser and S. Zink, New technical aspects in telepathology, Elec. J. Pathol. Histol. 6(3) (2000), No. 003-04.

[9] K. Kayser, J. Szymas and R. Weinstein, Telepathology Telecommunication, Electronic Education and Publication in Pathology, Springer, Heidelberg, New York, 1999.

[10] K. Kayser, G. Weisse, H. von Eberstein, I. Weisse and H. Frank, Histomorphologische Diagnostik am Telefon - Vision oder Realitaet, Labor Praxis (Nov. 1989), 1020-1024.

[11] K. Kayser and G. Kayser, Basic Aspects of and Recent development of telepathology in Europe with specific emphasis on quality assurance, J. Anal. Quant. Cytol. Histol. 21 (1999), 319-328.

[12] K. Kayser, Telemedizin, Wiener Klin. Wschr. 108 (1996), 932-940.

[13] M. Schiffer, Legal aspect of telepathology, Zetralbl. Pathol. 138 (1992), 393-394.

[14] P. Schwarzmann, B. Binder, R. Klose and M. Kaser, Histkom evaluation of active telepathology in fieldtests, Adv. Clin. Path. 2 (1998), 135-138.

[15] I. Tofukuji and Y. Ikono, Instrumentation and systems in Japanese telemedicine, Telemedicine (German-Japanese Workshop) (1999), 83-85.

[16] UICC International Telepathology Consultation Centre, opened in Berlin on July 3rd, 2000. 


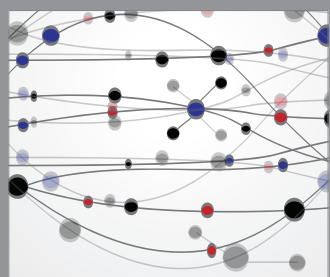

The Scientific World Journal
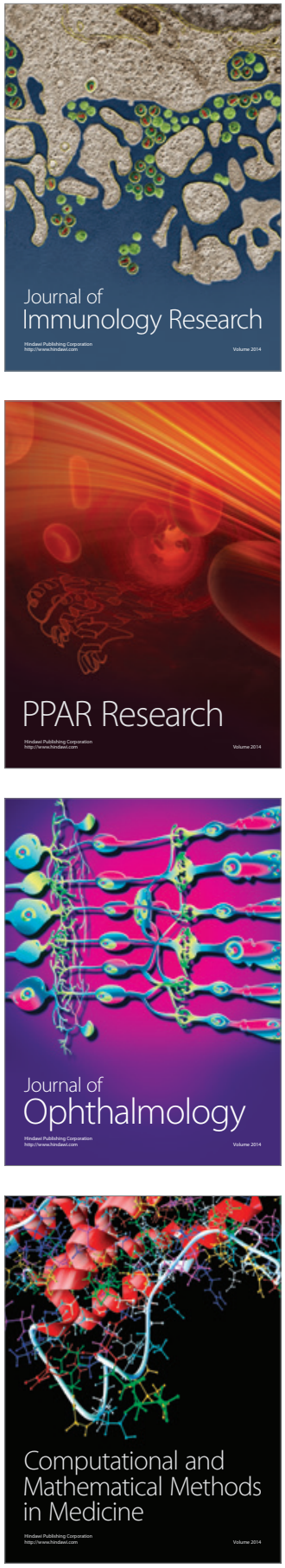

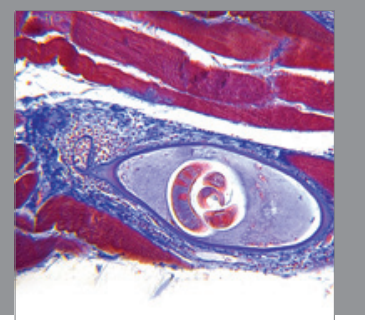

Gastroenterology

Research and Practice
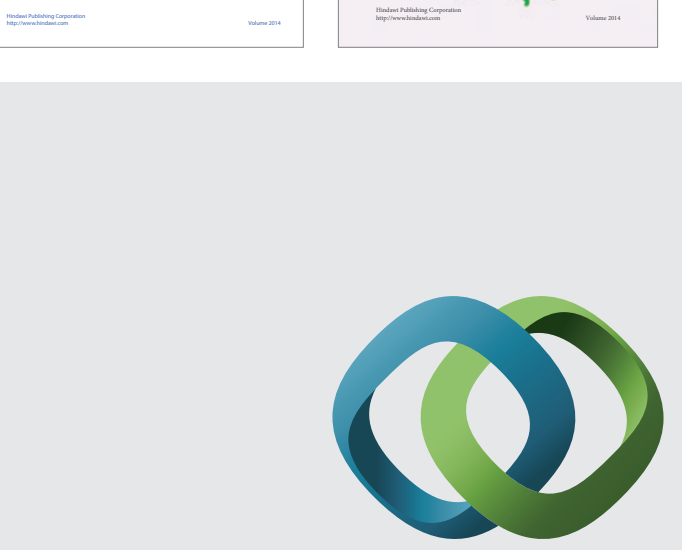

\section{Hindawi}

Submit your manuscripts at

http://www.hindawi.com
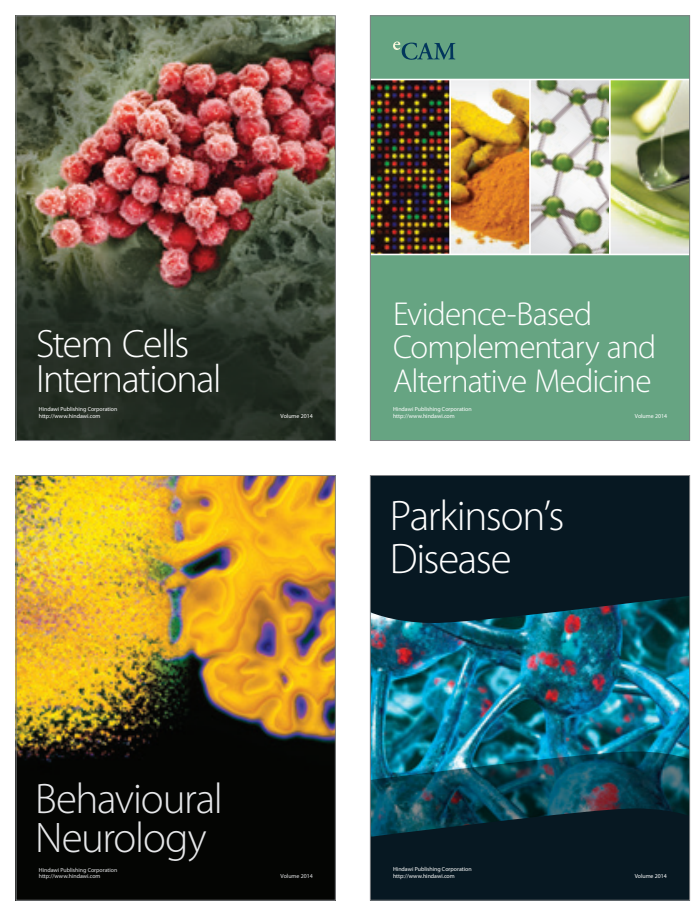

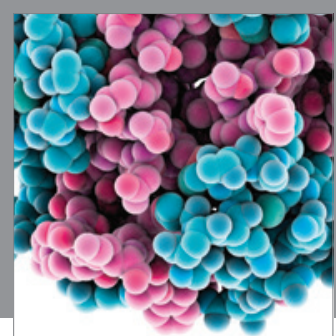

Journal of
Diabetes Research

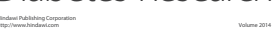

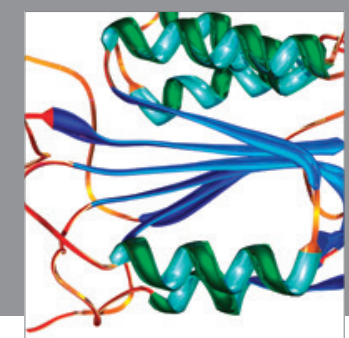

Disease Markers
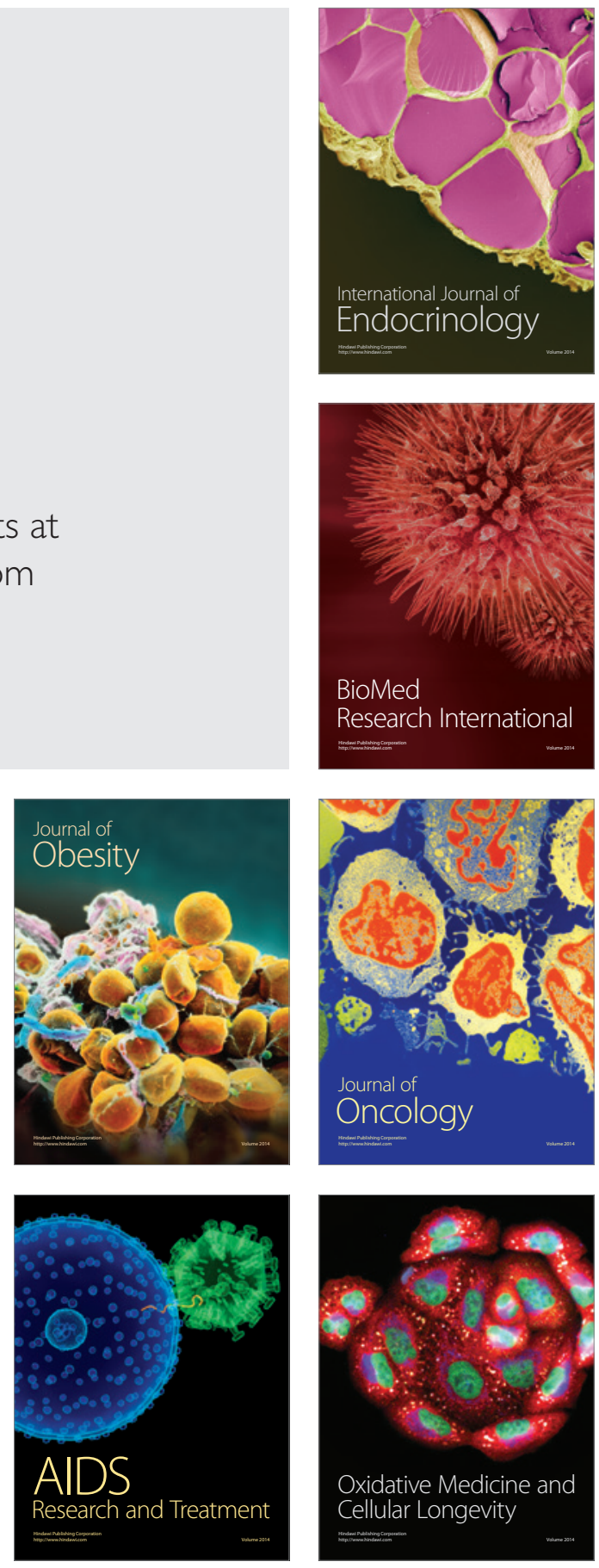